\title{
A national survey of infant feeding in Asian families: summary of findings relevant to oral health
}

\author{
R. G. Watt, 1
}

\begin{abstract}
In 1994 the Department of Health commissioned a survey of early feeding practices within the Asian community. The survey conducted by the Office for National Statistics (ONS) was designed to assess from a nationally representative sample of infants from the Bangladeshi, Indian and Pakistani communities from across England their feeding practices from birth to 15 months. A small sample of White infants were also included in the sample although they cannot be considered as nationally representative of the majority White population in England. Data was collected from 2382 mothers in total. The survey was carried out between 1994 and 1996 and was published in 1997. This article will summarise the main findings relevant to oral health. These include patterns of breastfeeding, use of bottles, care and advice on infant feeding, weaning practices and drinks consumption. Implications for oral health promotion are considered.
\end{abstract}

\begin{abstract}
Caries levels in the primary dentition are

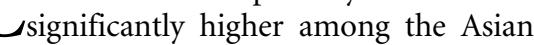
population in the UK than the majority White population. ${ }^{1-3}$ (Asian is being used as a term to include individuals of Indian, Pakistani or Bangladeshi extraction irrespective of the country of birth or nationality.) The reasons for these differences are not clear although income and social class may be key explanatory factors. ${ }^{4-5}$ Certain early feeding practices may however also be linked to higher caries levels among some Asian groups. ${ }^{6,7}$ Local studies assessing the feeding and weaning practices of Asian babies born to mothers living in England indicate that these babies are not achieving their full growth potential, due in part to early feeding practices. ${ }^{8-10}$

Although regular national surveys of infant feeding practices are carried out every 5 years, ${ }^{11}$ the samples have not been
\end{abstract}

${ }^{1}$ Senior Lecturer, Department of Epidemiology and

Public Health, University College London, 1-19

Torrington Place, London WC1E 6BT REFEREED PAPER

Received 23.12.98; accepted 03.06.99

(C) British Dental Journal 2000; 188: 16-20 large enough to enable analysis by different minority ethnic group. Recognising the need for a large scale survey of early feeding practices within the Asian community, the Department of Health commissioned a national survey in 1994. The survey was designed to examine a nationally representative group of infants from the Bangladeshi, Indian and Pakistani communities across England to determine their feeding practices from birth to 15 months and to assess the factors influencing their mothers feeding choices. $^{12}$

\section{In brief}

- This paper summarises the findings of the first national survey of infant feeding patterns among the Bangladeshi, Pakastani and Indian communities across England.

- The study has highlighted interesting differences in infant feeding practices between the different minority ethnic groups.

- It is unclear however whether these differences are caused by cultural or socio-economic factors.
An improved understanding of the early feeding practices of Asian infants may help to explain general and oral health ethnic inequalities. This paper will highlight the results of the Infant Feeding in Asian Families $^{12}$ survey which are most relevant to oral health and will then discuss the implications of these results for oral health promotion.

\section{Survey design and methods}

The survey was carried out by the Social Survey Division of the Office for National Statistics (ONS). The sample was selected to be representative of all babies born to mothers of Bangladeshi, Indian and Pakistani origin living in England. The 41 local authority areas selected for the sample covered $95 \%$ of the Asian population at the time of the 1991 Census. The sample was selected from each area's birth register. Mothers of the sampled babies were interviewed on four occasions, when the baby was approximately 6-10 weeks, 5 months, 9 months and 15 months. Data were collected between October 1994 and January 1996.

Interviews were face-to-face and carried out by trained ONS interviewers with the help of interpreters where appropriate. Interviews assessed feeding practices from birth to 15 months, factors influencing mother's choices over infant feeding and sources of information and support provided to mothers. (Information on the growth of babies was also collected but is not reported in this paper). Ethnicity classification was based upon the mothers assessment of which ethnic group the mother considered she belonged.

A small sample of White mothers was also chosen because they lived in the same areas as the Asian mothers. The White group however cannot be considered as nationally representative of the White population in England.

\section{Mothers interviewed}

Interviews were achieved with $86 \%$ of eligible respondents at the first interviews, $94 \%$ of eligible respondents at both the sec- 
ond and third interview, and $92 \%$ at the fourth interview. This resulted in $71 \%$ $(2,382)$ of mothers who were originally eligible being interviewed at the fourth stage.

The ethnic groups had very different social and economic characteristics (Table 1). In general, the White group had smaller household size, were more likely to have a working parent and had a higher level of income compared with the Asian groups. Among the Asian groups, the Bangladeshi mothers were more likely to live with larger families, have a poorer understanding of English and have the lowest level of income compared with the Pakistani and Indian mothers.

\section{Patterns of breastfeeding}

The highest incidence of breastfeeding in all ethnic groups was among mothers of first babies. However the incidence of breastfeeding was much higher for Asian mothers, 90\% among Bangladeshi, $82 \%$ among Indian and $76 \%$ among Pakistani mothers, compared with White mothers, $62 \%$ of whom had ever breastfed. The pattern of breastfeeding was different between the ethnic groups. Of mothers who started to breastfeed, Pakistani and Bangladeshi mothers stopped breastfeeding much sooner than either Indian or White mothers. For example, by the time their babies were 4-months-old, of those who started to breastfeed, 39\% of White, $34 \%$ of Indian, $25 \%$ of Bangladeshi and 21\% of Pakistani mothers were still breastfeeding. When asked why they had stopped breastfeeding, the most frequent reasons were lack of milk and the baby not sucking.

\section{Bottle feeding}

When asked about bottle feeding, $10 \%$ of Bangladeshi, $24 \%$ of Pakistani, $18 \%$ of Indian and $38 \%$ of White mothers reported that their babies were only ever bottle fed. The pattern of bottle feeding from 9 weeks to 15 months among the different ethnic groups is shown in Figure 1. At 9 months about $95 \%$ of all babies were bottle fed, and at 15 months at least $90 \%$ of the Asian groups and $75 \%$ of White children were still bottle fed, at least some of the time.

In contrast White children were more likely than the Asian children to be drinking milk from a cup, glass or beaker at 15 months - $67 \%$ of White children

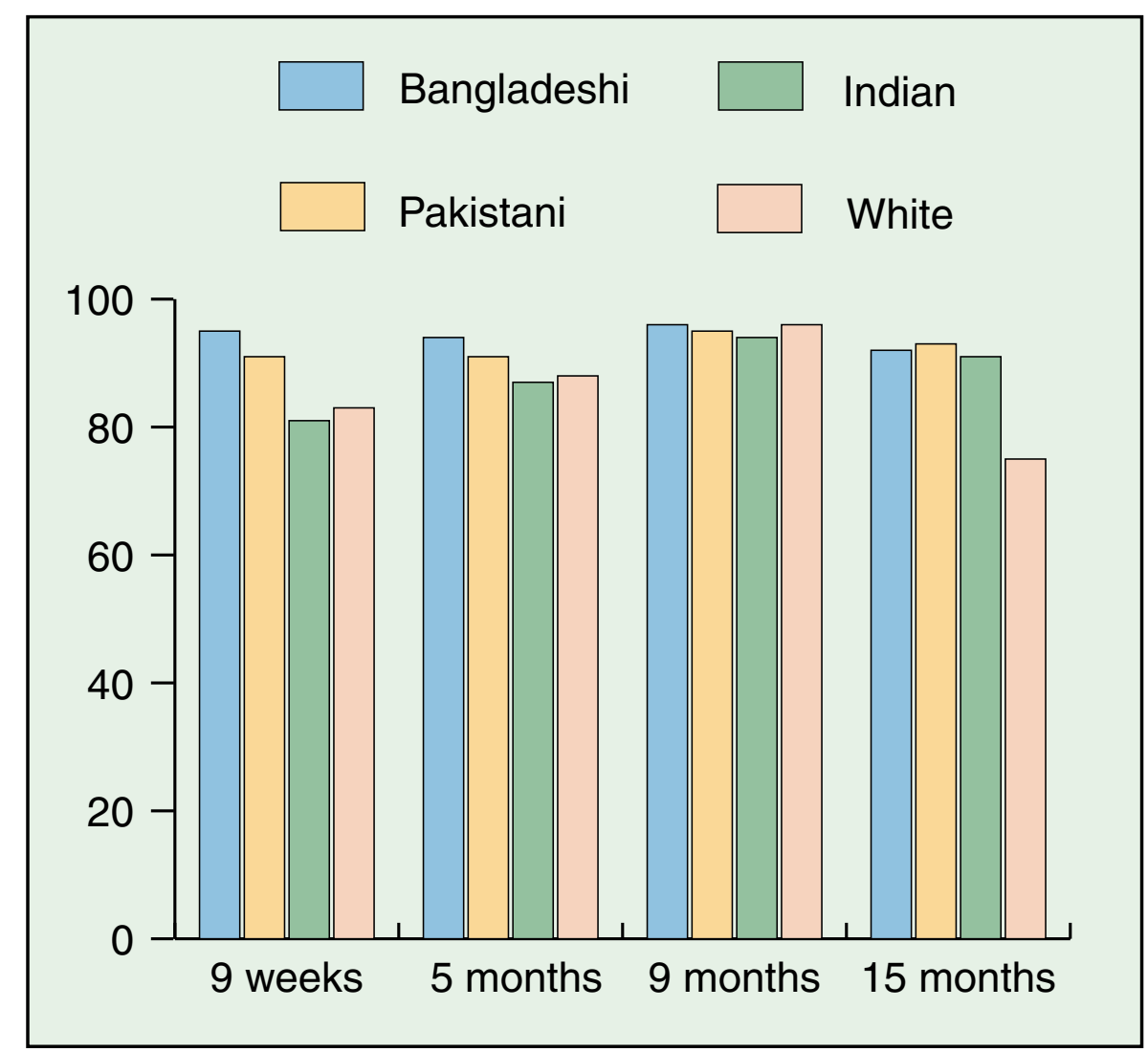

Fig. 1 Proportion of mothers giving milk from a bottle at each stage by ethnic group

compared with only $50 \%$ of Indian, $41 \%$ of Pakistani and $26 \%$ of Bangladeshi children.

At each interview mothers were asked if they added anything to their baby's bottle. When babies were on average 9-weeks-old, very few mothers added anything such as solid food or sugar to the milk in their baby's bottle. However as the child developed, Bangladeshi mothers were the most likely to have added something to the milk; by 9 months, $22 \%$ of Bangladeshi mothers reported adding something to the bottle compared with $12 \%$ of Pakistani, 9\% of Indian and $8 \%$ of White mothers. At 15 months, Bangladeshi mothers were still most likely of all ethnic groups to have added something to their baby's milk.
At 9 months, rusks were the most common addition to the baby's bottle in all Asian groups (added by $11 \%$ of Bangladeshi, $5 \%$ of Pakistani and $4 \%$ of Indian bottle feeding mothers). Bangladeshi mothers were the most likely to add baby rice or cereal $(8 \%)$. White mothers were the most likely to add milk shakes or other milk drinks (4\%). Between 2-3\% of Asian mothers reported adding sugar to their baby's bottles, whereas no White mothers added sugar.

When the children were 15-months-old, Bangladeshi mothers continued to be the most likely to add rusks/biscuits/baby rice/cereal to the bottle (23\% compared with $7 \%$ of Pakistani, $4 \%$ of Indian and $1 \%$ of White mothers). The proportion of Pakistani

\begin{tabular}{|c|c|c|c|c|c|}
\hline Table 1 & \multicolumn{5}{|c|}{ Social and economic characteristics of sample } \\
\hline \multicolumn{2}{|c|}{ Sample characteristic } & Bangladeshi & $\begin{array}{l}\text { Ethnic group } \\
\text { Pakistani }\end{array}$ & Indian & White \\
\hline \multicolumn{2}{|c|}{ Average household size } & 7 & 6.4 & 5.4 & 3.8 \\
\hline \multicolumn{2}{|c|}{$\begin{array}{l}\text { Mothers' understanding of } \\
\text { English: not at all/very little }\end{array}$} & $59 \%$ & $32 \%$ & $17 \%$ & N/A \\
\hline \multicolumn{2}{|c|}{ Husband/partner: unemployed } & $33 \%$ & $30 \%$ & $16 \%$ & $11 \%$ \\
\hline \multicolumn{2}{|c|}{ Receipt of income support } & $49 \%$ & $40 \%$ & $21 \%$ & $23 \%$ \\
\hline \multicolumn{2}{|c|}{ Mean gross weekly income } & $£ 139$ & $£ 152$ & $£ 244$ & $£ 296$ \\
\hline
\end{tabular}


mothers who added sugar to the bottle had increased to $10 \%$ compared with $5 \%$ or less in other groups. White mothers continued to be the most likely to give milk shakes or other milk drinks (13\%).

\section{Care and advice on feeding}

The Health Education Authority publications, The Pregnancy Book and Birth to Five are available free to all first time mothers. Of first time mothers who could read English, at least fairly well, Bangladeshi mothers were least likely to have been given these books, $32 \%$ of Bangladeshi mothers had not had either compared with $16 \%$ of Pakistani, $12 \%$ of Indian and $6 \%$ of White mothers.

The most commonly mentioned source of information on looking after children for Pakistani, Indian and White mothers, was commercially produced information obtained from shops or baby food companies. In contrast Bangladeshi mothers were more likely to obtain information from health clinics.

When their children were about 15months-old, mothers were asked who had given them most advice since the child was born. Of first time mothers, their mother or mother-in-law was mentioned most by all groups but particularly by Bangladeshi and Pakistani mothers, (Bangladeshi 56\%, Pakistani $50 \%$, Indian $38 \%$ and White mothers $35 \%)$. Health visitors or midwives were mentioned by around a quarter of mothers in all groups.

Of those mothers who expressed the desire for more information about feeding their child, weaning was the issue most wanted more information on (Bangladeshi $75 \%$, Indian and White $66 \%$ and Pakistani mothers $62 \%$ ). More than $30 \%$ also wanted more information on healthy diets for their child.

\section{Consumption of food}

At each interview, mothers were asked to recall all food the baby had eaten on the day before the interview. At the first interview, when the baby was around 9-weeks-old, rusks and rice cereals were the foods most frequently given by Indian and White mothers. The number of Bangladeshi and Pakistani mothers in the sample giving solid food at this age was too small for analysis.

When the baby was about 5 months,
Bangladeshi mothers (59\%) were most likely to have given desserts, or sweets and chocolate on the day before interview, compared with Pakistani $(44 \%)$, White $(41 \%)$ and Indian mothers (31\%).

When the baby was aged 9 months a very different pattern of eating emerged. White babies were twice as likely to eat biscuits and cakes, or sweets and chocolate as Asian babies. By the final interview when the children were aged around 15 months consumption of biscuits, cakes, sweets and chocolate had increased for all groups, but were still consumed more by White children than Asian children. For example, 31\% of White children ate sweets or chocolate on the day before interview, compared with $15 \%$ of Bangladeshi and Pakistani, and 12\% of Indian children. Data on the frequency of consumption of sweets and chocolate also revealed that White children consumed confectionery more frequently compared with Asian children. These feeding patterns have important implications for oral health.

To find out more about the decisions made on how to feed the child, mothers were asked whether there were foods they did not give the child and the reasons for this. Sugar was mentioned by mothers from all groups, although for White mothers $(37 \%)$ this was a particular concern. Concerns about sugar were most apparent when the child was 9-months-old. In all groups worries about sugar were reduced when the child was aged 15 months. White mothers were more likely than Asian mothers to report that they avoided foods that were bad for their child's teeth or would encourage him/her to develop a sweet tooth. Again these concerns were more common in all groups when the child was aged 9 months.

\section{Consumption of drinks}

When the babies were aged between 9-weeks and 9-months-old, mothers were asked about the types of drinks, apart from milk they usually gave their child. When the children were aged 15 months, they were asked to recall all drinks given the day before.

The most popular drink by far, given by mothers in all groups when the baby was about 9-weeks-old was plain or mineral water (Table 2). At about 5 months Bangladeshi mothers were still most likely to give water $(75 \%)$. Pakistani, Indian and White mothers were less likely to give water at this age than previously. The other main difference from the previous interview was that a much greater proportion of all mothers were giving fruit drinks, $75 \%$ of Pakistani and White mothers, $63 \%$ of Indian and $61 \%$ of Bangladeshi.

When the babies were around 9-monthsold, water continued to be the most frequently given drink, but the proportion of babies drinking water from the tap had increased for all groups, and was higher among Pakistani (31\%) and Bangladeshi (28\%) babies, than among Indian (17\%) and White babies (10\%). Between a quarter and a third of mothers in all groups gave pure or fresh fruit juice. Twenty per cent of White babies drank tea or coffee at this age, compared with $6 \%$ of Indian, $3 \%$ of Pakistani and $1 \%$ of Bangladeshi babies.

When the children were aged about 15 months, mothers were asked to recall the drinks given to the child on the previous day. A major change at this age was that babies were drinking water straight from the tap rather than boiled water. Asian children were still more likely to drink water than White children $-68 \%$ of Pakistani, $62 \%$ of Bangladeshi, $47 \%$ of Indian and $21 \%$ of White children drank tap water. Consumption of sweetened fruit drinks had almost doubled in all groups over the 6-month period $-26 \%$ of Pakistani, 24\% Indian, $22 \%$ Bangladeshi and 18\% White children drank sweetened fruit drinks.

\section{Significance of this study}

The results of this large scale survey of infant feeding practices in Asian families reveals some interesting issues relevant to explanations of oral health ethnic inequalities among pre-school children. However interpretation of the results of the survey must be viewed with a degree of caution. In accordance with the findings of the latest national health survey of ethnic minorities, the socio-economic position of minority ethnic groups is very different from the majority White population. ${ }^{13}$ In particular the Bangladeshi and Pakistani samples in this study were socially and economically the most disadvantaged. For example, compared with the White members of the sample, Bangladeshi mothers were three times 
more likely to have a partner/husband who was unemployed and have half the mean gross weekly income. The results presented have not been controlled for these economic differences. Therefore any differences between the ethnic groups may be caused by social class and economic differences rather than any cultural factors. Further analysis of the data is therefore required to fully explore explanations for the differences found between groups.

The most important findings relevant to oral health is that at 15 months at least $90 \%$ of the Asian children and 75\% of the White children were still using a bottle, at least some of the time. Only a quarter of Bangladeshi children were using a cup, glass or beaker at this age. This pattern of drinking is contrary to COMA recommendations that infants should be introduced to a cup from 6 months and by 1 year feeding from a bottle should be discouraged. ${ }^{14}$ In addition, Bangladeshi mothers were most likely to add something sweet to their baby's bottle, for example rusks, baby rice or cereals.

On the other hand, the results on consumption of sweet foods revealed quite different findings. Although Bangladeshi babies at 5 months were more likely to be given desserts, sweets or chocolate, by the age of 9 and 15 months, the White babies were twice as likely to eat biscuits, cakes, sweets or chocolate than the Asian babies. The White children also consumed confectionery on a more frequent basis than the other groups in the sample.

Interestingly the concern of mothers about sugar in their child's diet was most apparent when the child was 9-monthsold. By the age of 15 months this concern had reduced considerably in all groups. Why this should happen remains unclear. However a high proportion of mothers expressed a desire for more information on weaning in particular.

In relation to drinks consumption, some interesting results were uncovered. From the age of 5 months Pakistani and Bangladeshi infants were more likely to be given water than the Indian or White babies. This difference was maintained when the children were aged 9- and 15- months-old. Fruit drinks, a major source of non milk extrinsic sugars in the pre-school diet, were

\begin{tabular}{|c|c|c|c|c|c|}
\hline Table 2 & $\begin{array}{l}\text { Proportion o } \\
\text { when boloy }\end{array}$ & $\begin{array}{l}\text { of mothers whr } \\
\text { was oged } 9 \text { w }\end{array}$ & $\begin{array}{l}\text { eve drinks } \\
\text { ks by ethn }\end{array}$ & $\begin{array}{l}\text { ler then } \\
\text { oup }\end{array}$ & \\
\hline Propor & n of mothers & & Ethni & roup & \\
\hline & & $\underset{\%}{\text { Bangladeshi }}$ & $\begin{array}{c}\text { Pakistani } \\
\%\end{array}$ & $\begin{array}{c}\text { Indian } \\
\%\end{array}$ & $\begin{array}{c}\text { White } \\
\%\end{array}$ \\
\hline Plain or & ieral water & 71 & 47 & 53 & 41 \\
\hline Sweeter & water & 6 & 16 & 15 & 5 \\
\hline Gripe w & & 2 & 6 & 3 & 1 \\
\hline Herbal & & 0 & 5 & 2 & 6 \\
\hline Fruit juic & & 9 & 12 & 8 & 17 \\
\hline Other & & 0 & 1 & 0 & 0 \\
\hline No drin & jiven & 14 & 16 & 20 & 33 \\
\hline Base $=$ & & 610 & 731 & 934 & 619 \\
\hline
\end{tabular}

given to more than $60 \%$ of the sample when the infant was 5-months old. Again, contrary to COMA recommendations, ${ }^{14} 20 \%$ of White babies drank tea or coffee from the age of 9 months. (The tannin present in tea and coffee inhibits iron absorption in preschool children.)

In view of the socio-economic differences between the different groups in the sample firm conclusions cannot be reached with the data at this stage. However the results indicate that up to 5 months of age Bangladeshi and Pakistani babies may consume a diet higher in non milk extrinsic sugars than White and Indian babies. This is mainly caused by their pattern of bottle feeding and higher consumption of sweetened foods. However by 9 months and older White children consume more confectionery and fruit juices.

These findings from this large scale national survey support the published results from smaller local surveys. For example, Williams et al. showed that most inner city Asian infants from Leeds were still feeding from a bottle at the age of 2 years and that two-thirds of the milk feeds were sweetened. They also revealed that Asian infants were far more likely to drink plain water in addition to milk, although in contrast White infants drank considerably more tea. ${ }^{6}$ In a subsequent study Asian mothers' attitudes to infant feeding practices were assessed through group discussions. This revealed that many mothers rejected health professional's advice to discontinue using a feeding bottle by 12 months because of a concern that this change might stop their infants drinking milk. Sugar was added to milk to ensure that more milk would be consumed or because of the perceived beneficial qualities of sugar. ${ }^{7}$

\section{Implications of this first national study of infant feeding in Asian families}

What implications can be drawn from this study? First more research is clearly needed to explore fully early dietary practices among minority ethnic groups. In particular the impact of economic issues, as opposed to cultural factors, needs to be explored further. At present very limited information is available to design effective health promotion interventions. ${ }^{15}$ Oral health promoters need to however recognise the socio-economic disadvantage experienced by particular ethnic groups when designing and implementing policies. In addition, it is essential that future health promotion strategies recognise the factors that determine infant feeding practices and adopt a range of appropriate complemen- 
tary measures. Members of the minority ethnic groups should be actively involved in the development of such strategies.

1 Bedi R. Ethnic indicators of dental health for young Asian school children resident in areas of multiple deprivation. Br Dent J 1989; 166: 331-334.

2 Bradnock G, Jadaua S, Hamburger R. The dental health of indigenous and nonindigenous infant school children in West Birmingham. Community Dent Health 1988; 1: 139-150.

3 Prendergast M, Williams S, Curzon M. An assessment of dental caries prevalence among Gujurati Pakistani and White Caucasian five year old children resident in Dewsbury, West Yorkshire. Community Dent Health 1989; 6: 223-232.

4 Plamping D, Bewley B, Gelbier S. Dental health and ethnicity. Br Dent J 1985; 168: 24-26.

5 Bedi R, Uppal R. The oral health of minority ethnic communities in the United Kingdom. Br Dent J 1995; 179: 421-425.

6 Williams S, Sahota P, Fairpo C. Infant feeding practices within white and Asian communities in inner-city Leeds. J Hum Nutr Diet 1989; 2: 325-338.

7 Williams S, Sahota P. An enquiry into the attitudes of Muslim Asian mothers regarding infant feeding practices and dental health. J Hum Nutr Diet 1990; 3 : 393-401.

8 Duggan M, Harbottle L. The growth and nutritional status of healthy Asian children aged 4-40 months living in Sheffield. Br J Nutr 1996; 76: 453-471.

9 Warrington S, Storey D. Comparative studies of Asian and Caucasian children 2. Nutrition, feeding practices and health. Eur J Clin Nutr 1988; 42: 69-80.
10 Harris R, Armstrong D, Ali R, Loynes A. Nutritional survey of Bangladeshi children aged under 5 years in the London borough of Tower Hamlets. Arch Dis Child 1983; 58: 428-432.

11 Foster K, Cheesbrough S, Lader D. Infant feeding 1995. London: HMSO, 1997.

12 Thomas M, Avery, V. Infant feeding in Asian families. Early feeding practices and growth. London: The Stationary Office, 1997.

13 Nazaroo J. The health of Britain's ethnic minorities: findings from a national survey. London: Policy Studies Institute, 1997.

14 Department of Health. Weaning and the weaning diet. Report on Health and Social Subjects No. 45. London: HMSO, 1994.

15 Tedstone A, Dunce N, Aviles M, Shetty P, Daniels L. Effectiveness of interventions to promote healthy feeding in infants under one year of age: a review. London: Health Education Authority, 1998.

\section{British Dental Journal Publication Times}

The British Detal Journal is pleased to be able to announce that average acceptance to publication times the period of time after the paper has been refereed and approved until its final appearance in the Journal remained as fast in the second half of 1999 as in the first half.

Current publications times for the various sections in the Journal are as follows:

Opinion papers -4 months

Practice papers -7 months

Research -3 months

Education -3 months

In some instances the publication times can be substantially faster and we anticipate an improvement in the publication times of practice papers in volume 188.

\section{Submitting illustrations to the BDJ}

Authors submitting manuscripts for publication in the BDJ are reminded that two copies of all illustrations must be supplied. This will assist in speeding up the refereeing process manuscripts and illustrations are always sent to referees and a set of illustrations is required at the editorial office for reference. If you choose to submit 35-mm transparencies then one set of these and one set of prints (colour or black \& white) will be acceptable.

We strongly advise authors to keep copies of all illustrations submitted in case letters are lost or damaged in transit. Please do not send glassmounted transparencies - even when securely wrapped the glass will often arrive cracked or shattered, resulting in damage to the surface of the slide which usually renders it unsuitable for reproduction. 